\title{
Hydromagnetic Free Convective Rivlin - Ericksen Flow through a Porous Medium with Variable Permeability
}

\author{
G. Noushima Humera ${ }^{1}$, M.V. Ramana Murthy ${ }^{2}$, M. ChennaKrishna Reddy ${ }^{2}$, \\ Rafiuddin $^{3}$, A. Ramu ${ }^{4}$, and S. Rajender ${ }^{1}$ \\ ${ }^{1}$ Department of Mathematics, Methodist College of Engg and Tech, Hyderabad, India \\ ${ }^{2}$ Department of Mathematics, Osmania University, Hyderabad, India \\ ${ }^{3}$ Department of Humanities and Sciences, CVR College of Engg and Tech, Ibrahim \\ Patnam, RR Dist, India \\ ${ }^{4}$ Department of Mathematics, BITS-Pilani, Hydeabad, India
}

\begin{abstract}
A theoretical analysis of free convective two dimensional unsteady flow of a visco-elastic incompressible fluid through a porous medium bounded by an infinite vertical porous plate subjected to a uniform suction is presented under the influence of a uniform transverse magnetic field. Approximate solutions for velocity distribution,fluctuating parts of the velocity profiles,amplitude and phase lead of the skin friction at the plate has been found by using perturbation technique. The effects of various parameters has been studied, discussed numerically and shown graphically. And numerical values of coefficient of skin friction for various values of physical parameters are presented.
\end{abstract}

Key words: Rivlin - Ericksen fluid, Porous medium, Suction and Free convection.

\section{Introduction}

Raptis et.al [1],Raptis [2] and Raptis \&Perdikis [3] studied the steady free convective flow through a porous medium bounded by an infinite vertical plate. In above problem porous medium was considered to be homogeneous. In fact, a porous material containing the fluid is a non -homogenous medium and there can be numerous inhomogeneties present in the porous medium. Because of its possible application in design of stream displacement processes in oil recovery and various 
geothermal system. Chandrasekhara et. al [ 4 ], Vedhanayagam et. al [ 5 ] have considered the permeability variation to study the buoyancy induced flow behaviour adjacent to a horizontal heated surface in a porous medium and porous medium and have shown that variable permeability has a greater influence on velocity distribution.Singh et.al[6] investigated the effects of permeability variation on free convective flow in a porous medium bounded by a vertical porous wall when the permeability varies in a direction. Maharshi \& Tak [ 7 ] studied fluctuating free convection through porous medium due to infinite vertical plate with constant heat flux. Two dimensional MHD oscillatory flow along a uniform moving infinite vertical porous plate bounded by porous medium studied by Ahmed \& Ahmed [8 ]. Unsteady two dimensional flow and heat transfer through an elastic - viscous liquid along an infinite hot vertical porous medium studied by Sharma \& Sharma[9]. Sharma \& Yadav [10] studied the three dimensional flow and heat transfer through porous medium bounded by a porous vertical surface with variable permeability and heat source. Sreekanth et.al [11] studied hydromagnetic free convective flow through a porous medium with variable permeability. Noushima et.al [12] studied unsteady MHD memory flow and heat transfer over a moving continuous porous horizontal surface.

In this paper,we have studied the problem of Sreekanth et.al with Rivlin Erciksen [13] fluid whose constitutive equation gives covers both elastic and inelastic fluids and large number of fluids like aqueous solution of polyacrylamid ; poly isobutylene are well covered by this constitutive equation.

\section{Formulation of the Problem}

The permeability of the porous medium is assumed to be of the form

$$
\mathrm{K}^{\prime}\left(\mathrm{t}^{\prime}\right)=\mathrm{K}_{0}^{\prime}\left(1+\varepsilon \mathrm{e}^{\mathrm{i} \omega^{\prime} \mathrm{t}^{\prime}}\right)
$$

where $\mathrm{K}_{0}{ }^{\prime}$ is the mean permeability of the medium,

$\omega^{\prime}$ is the frequency of the fluctuation,

$\mathrm{t}^{\prime}$ is the time and $\varepsilon(<<1)$ is a constant quantity.

We consider the flow of incompressible memory fluid through a porous medium bounded by an infinite vertical porous plate with constant suction, under the influence of a uniform transverse magnetic field .The $\mathrm{x}-$ axis is taken along the plate in the upward direction and a straight line perpendicular to that as the y-axis. All the fluid properties are assumed constant except that the influence of the density variation with temperature is considered only in the body force term. The magnetic field of small intensity $\mathrm{H}_{0}$ is introduced in the $\mathrm{y}$ - direction. Since the fluid is slightly conducting, the magnetic Reynolds number is much less than unity and hence the induced magnetic field is neglected in comparison with the applied magnetic field following Sparrow and Cess [14]. In the absence of any input electric field, the equations governing the flow under Boussineqs approximation are 


$$
\begin{aligned}
& \mathrm{u}_{\mathrm{t}}+v \mathrm{u}_{\mathrm{y}}=\mathrm{g} \beta(\mathrm{T}-\mathrm{T} \infty)+v \mathrm{u}_{\mathrm{yy}}+\beta_{1}\left(\mathrm{u}_{\text {tyy }}+v \mathrm{u}_{\mathrm{yyy}}\right)-v \mathrm{u} / \mathrm{K}^{\prime}\left(\mathrm{t}^{\prime}\right)- \\
& \sigma \mu \mathrm{e}^{2} \mathrm{H}_{0}^{2} \mathrm{u} / \rho \\
& \mathrm{v}_{\mathrm{y}}=0 \\
& \mathrm{~T}_{\mathrm{t}}+v \mathrm{~T}_{\mathrm{y}}=\left(\mathrm{K}_{\mathrm{T}} / \rho \mathrm{C}_{\mathrm{p}}\right) \mathrm{T}_{\mathrm{yy}}
\end{aligned}
$$

where $\mathrm{u}$ and $\mathrm{v}$ are the components of the velocity in the $\mathrm{x}$ and $\mathrm{y}$ direction respectively, $\mathrm{g}$ is the acceleration due to gravity , $\beta$ the coefficient of volume expansion, $\beta_{1}$ kinematic viscoelasticity. $\rho, \mu, v, K_{T}, C_{p}$ are the density,viscosity, kinematic viscosity thermal conductivity and specific heat if the fluid at constant pressure, $t$ is the time, $\sigma$ the electrical conductivity of the fluid and $\mu_{\mathrm{e}}$ the magnetic permeability. $\mathrm{T}_{\mathrm{w}}$ and $\mathrm{T}_{\infty}$ are the temperature of the plate and temperature of the fluid far away from the plate.

$$
\begin{aligned}
& \text { Equation (2) yields } \\
& \mathrm{v}=-\mathrm{v}_{0}
\end{aligned}
$$

where $\mathrm{v}_{0}>0$ is a constant and the negative sign indicates that the suction is towards the plate. It is worth while to mention that the basic flow in the medium is entirely due to buoyancy force caused by temperature difference between the wall and the medium.

The boundary conditions of the problem are :

$$
\left.\begin{array}{l}
\mathrm{y}=0: \mathrm{u}=0, \mathrm{~T}=\mathrm{T}_{\mathrm{w}} \\
\mathrm{y} \rightarrow \infty: \mathrm{u}=0, \mathrm{~T}=\mathrm{T}_{\infty}
\end{array}\right\}
$$

Introducing the following non-dimensional quantities :

$$
\begin{array}{lll}
\overline{\mathrm{y}}=\mathrm{y} \mathrm{v}_{0} / \mathrm{v} & \overline{\mathrm{t}}=\mathrm{t} \mathrm{v}_{0} / 4 \mathrm{v} & \bar{\omega}=4 \mathrm{v \omega} / \mathrm{v}_{0}{ }^{2} \\
\overline{\mathrm{u}}=\mathrm{u} / \mathrm{v}_{0} & \bar{\theta}=\mathrm{T}-\mathrm{T}_{\infty} / \mathrm{T}_{\omega}-\mathrm{T}_{\infty} & \mathrm{Gr}=v \mathrm{~g} \beta\left(\mathrm{T}_{\omega}-\mathrm{T}_{\infty}\right) / \mathrm{v}_{0}^{3} \\
\mathrm{Pr}=\mu \mathrm{C}_{\mathrm{p}} / \kappa & \mathrm{K}_{0}=\mathrm{K}_{0}{ }^{2} \mathrm{v}_{0}{ }^{2} / \mathrm{v}^{2} & \mathrm{M}=\sigma \mu \mathrm{e}^{2} \mathrm{H}_{0}{ }^{2} \mathrm{v} / \rho \mathrm{v}_{0}{ }^{2} \\
\mathrm{R}_{\mathrm{m}}=\beta_{1} \mathrm{v}_{0}{ }^{2} / \mathrm{v}^{2} & \\
\text { using (6), (1) and (3) reduces to (dropping the bars ). }
\end{array}
$$




$$
\begin{aligned}
1 / 4 u_{t}-u_{y}= & G r \theta+u_{y y}+R_{m}\left(1 / 4 u_{t y y}-u_{y y ~}\right)- \\
& u / K_{0}\left(1+\varepsilon e^{i \omega t}\right)-M u \\
1 / 4 \theta_{t}-\theta_{y}= & 1 / \operatorname{Pr} \theta_{y y}
\end{aligned}
$$

where subscripts denotes the differentiation. And $\mathrm{Gr}, \operatorname{Pr}, \mathrm{K}{ }_{0}, \mathrm{M}$ and $\mathrm{R}_{\mathrm{m}}$ are Grashoff Number, Prandtl Number, Permeability Parameter, Magnetic Parameter and Magnetic Reynolds Number respectively.

The non-dimensional boundary conditions are :

$$
\left.\begin{array}{l}
y=0: u=0, \theta=1 \\
y \rightarrow \infty: u=0, \theta=0
\end{array}\right\}
$$

In the neighbourhood of the plate, we take solution of the form

$$
\begin{aligned}
& u(y, t)=u_{0}(y)+\varepsilon e^{i \omega t} u_{1}(y) \\
& \theta(y, t)=\theta_{0}(y)+\varepsilon e^{i \omega t} \theta_{1}(y)
\end{aligned}
$$

Substituting (10) and (11) into (7) and (8), and comparing the harmonic and non harmonic terms, we obtain

$$
\begin{gathered}
\mathrm{R}_{\mathrm{m}} \mathrm{u}_{0}{ }^{111}-\mathrm{u}_{0}{ }^{11}-\mathrm{u}_{0}{ }^{1}+\mathrm{L}_{1} \mathrm{u}_{0}=\mathrm{Gr} \theta_{0} \\
\mathrm{R}_{\mathrm{m}} \mathrm{u}_{1}{ }^{111}-\mathrm{u}_{1}{ }^{11}-\mathrm{u}_{1}{ }^{1}\left(1+\mathrm{R}_{\mathrm{m}} \mathrm{i} \omega / 4\right)+\mathrm{u}_{1} \mathrm{~L}_{2}=\mathrm{Gr} \theta_{1}+ \\
\mathrm{u}_{0} / \mathrm{k}_{0}
\end{gathered}
$$

where the primes denotes differentiation with respect to $\mathrm{y}$.

Now the boundary conditions (9) reduces to

$$
\left.\begin{array}{l}
\mathrm{y}=0: \mathrm{u}_{0}=\mathrm{u}_{1}=0, \theta_{0}=1, \theta_{1}=0 \\
\mathrm{y} \rightarrow \infty: \mathrm{u}_{0}=\mathrm{u}_{1}=0, \theta_{0}=\theta_{1}=0
\end{array}\right\}
$$


The equations ( 12 ) and (13) are third order differential equations, due to presence of elasticity. Since the viscoelasticity coefficient $\beta_{1}$ is very small, therefore $\mathrm{u}_{0}, \mathrm{u}_{1}$ is expanded using Beard and Walters rule [15]

$$
\left.\begin{array}{c}
\mathrm{u}_{0}=\mathrm{u}_{00}+\mathrm{R}_{\mathrm{m}} \mathrm{u}_{01} \\
\mathrm{u}_{1}=\mathrm{u}_{11}+\mathrm{R}_{\mathrm{m}} \mathrm{u}_{12}
\end{array}\right\}
$$

\section{Zeroth - Order of $\mathbf{R}_{\mathrm{m}}$ :}

$$
\begin{aligned}
& \mathrm{u}_{00}{ }^{11}+\mathrm{u}_{00}{ }^{1}-\mathrm{u}_{00} \mathrm{~L}_{1}=- \text { Gr } \mathrm{e}^{- \text {Pry }} \\
& \mathrm{u}_{11}{ }^{11}+\mathrm{u}_{11}{ }^{1}-\mathrm{u}_{11} \mathrm{~L}_{2}=-\mathrm{u}_{00} / \mathrm{k}_{0}
\end{aligned}
$$

\section{First - Order of $\mathbf{R}_{\mathbf{m}}$ :}

$$
\begin{aligned}
& \mathrm{u}_{01}{ }^{11}+\mathrm{u}_{01}{ }^{1}-\mathrm{u}_{01} \mathrm{~L}_{1}=\mathrm{u}_{00}{ }^{111} \\
& \mathrm{u}_{12}{ }^{11}+\mathrm{u}_{12}{ }^{1}-\mathrm{u}_{12} \mathrm{~L}_{2}=\mathrm{u}_{11}{ }^{111}-\mathrm{i} \omega / 4 \mathrm{u}_{11}{ }^{11}-\mathrm{u}_{01} / \mathrm{k}_{0}
\end{aligned}
$$

The corresponding boundary conditions are :

$$
\left.\begin{array}{l}
\mathrm{y}=0: \mathrm{u}_{00}=\mathrm{u}_{01}=\mathrm{u}_{11}=\mathrm{u}_{12}=0 \\
\mathrm{y} \rightarrow \infty: \mathrm{u}_{00}=\mathrm{u}_{01}=\mathrm{u}_{11}=\mathrm{u}_{12}=0
\end{array}\right\}
$$

solving (18) to (21) under the boundary conditions (22) and substituting the obtained solution into (12) and (13). Using this in equation (10) \& (11), velocity field can be expressed in terms of the fluctuating parts as

$$
\begin{aligned}
\mathrm{u}(\mathrm{y}, \mathrm{t})= & {\left[\mathrm{L}_{0}\left(\mathrm{e}^{-\mathrm{m}_{1} \mathrm{y}}-\mathrm{e}^{-\operatorname{Pry}}\right)+\mathrm{R}_{\mathrm{m}}\left(\mathrm{G}_{1}\left(\mathrm{e}^{-\operatorname{Pry}}-\mathrm{e}^{-\mathrm{m}_{1} \mathrm{y}}\right)-\mathrm{G}_{2} \mathrm{y} \mathrm{e}^{-\mathrm{m}_{1} \mathrm{y}}\right)\right]+} \\
& \varepsilon\left(\cos \omega \mathrm{t} \mathrm{M}_{\mathrm{r}}-\sin \omega \mathrm{t} \mathrm{M}_{\mathrm{i}}\right)
\end{aligned}
$$

where $\mathrm{M}_{\mathrm{r}}+\mathrm{i} \mathrm{M}_{\mathrm{i}}=\mathrm{u}_{1}(\mathrm{y})$.

$$
\begin{aligned}
& \mathrm{M}_{\mathrm{r}}=\mathrm{L}_{6} \mathrm{e}^{-\mathrm{ay}} \sin \text { by }-\mathrm{e}^{-\mathrm{ay}}\left(\mathrm{L}_{9} \sin \mathrm{by}+\mathrm{L}_{8} \cos \text { by }\right)+\mathrm{L}_{8} \mathrm{e}^{-\mathrm{Pry}}+ \\
& \mathrm{R}_{\mathrm{m}}\left[\mathrm{e}^{-\mathrm{ay}}\left(\mathrm{L}_{40} \cos \text { by }+\mathrm{L}_{41} \sin \text { by }\right)-\mathrm{y} \mathrm{e}^{-\mathrm{ay}}\left(\mathrm{L}_{53} \sin \text { by }-\mathrm{L}_{54} \operatorname{cosby}\right)\right. \\
& \left.+\mathrm{L}_{49} \mathrm{e}^{-\mathrm{m}_{1} \mathrm{y}}-\mathrm{L}_{51} \mathrm{e}^{-\mathrm{Pry}}\right] \\
& \mathrm{M}_{\mathrm{i}}=\mathrm{L}_{6} \mathrm{e}^{-\mathrm{ay}} \cos \text { by }-\mathrm{e}^{-\mathrm{ay}}\left(\mathrm{L}_{9} \cos \text { by }-\mathrm{L}_{8} \sin \text { by }\right)-\mathrm{L}_{6} \mathrm{e}^{-\mathrm{m}_{1} \mathrm{y}_{+}} \\
& \mathrm{L}_{9} \mathrm{e}^{-\mathrm{Pry}}+\mathrm{R}_{\mathrm{m}}\left[\mathrm{e}^{-\mathrm{ay}}\left(\mathrm{L}_{41} \cos \text { by }-\mathrm{L}_{40} \sin \text { by }\right)-\mathrm{y} \mathrm{e}^{-\mathrm{ay}}\right.
\end{aligned}
$$




$$
\begin{aligned}
& \left.\quad\left(\mathrm{L}_{53} \cos \text { by }+\mathrm{L}_{54} \sin \text { by }\right)+\left(\mathrm{L}_{50}+\mathrm{y} \mathrm{L}_{17}\right) \mathrm{e}^{-\mathrm{m}_{1} \mathrm{y}}-\mathrm{L}_{52} \mathrm{e}^{-\operatorname{Pry}}\right] \\
& \theta(\mathrm{y})=\mathrm{e}^{-\operatorname{Pry}}
\end{aligned}
$$

Hence, the expression for the transient velocity, for $\omega t=\pi / 2$ is given by

$$
\mathrm{u}(\mathrm{y}, \pi / 2 \omega)=\mathrm{u}_{0}(\mathrm{y})-\varepsilon \mathrm{M}_{\mathrm{i}}
$$

The expression for the skin - friction at the plate in terms of its amplitude and phase as

$$
\begin{aligned}
& \mathrm{C}_{\mathrm{f}}=\mathrm{Z} \cdot / \mathrm{f} \mathrm{v}_{0}^{2}=(\partial \mathrm{u} / \partial \mathrm{y})_{\mathrm{y}=0} \\
& \mathrm{Z}=\mathrm{L}_{0}\left(\operatorname{Pr}-\mathrm{m}_{1}\right)+\mathrm{R}_{\mathrm{m}}\left[\mathrm{G}_{1}\left(\mathrm{~m}_{1}-\mathrm{Pr}\right)-\mathrm{G}_{2}\right]+\varepsilon \mathrm{e}^{\mathrm{i} \omega \mathrm{t}}\left(\mathrm{N}_{\mathrm{r}}+\mathrm{iN}_{\mathrm{i}}\right)
\end{aligned}
$$

Where

$$
\begin{aligned}
& N_{r}= b L_{6}+a L_{8}-b L_{9}-\operatorname{Pr} L_{8}+R_{m}\left[-a L_{40}+b L_{41}+L_{54}-m_{1} L_{49}+\operatorname{Pr} L_{51}\right] \\
& N_{i}=-a L_{6}+a L_{9}+b L_{8}+m_{1} L_{6}-\operatorname{Pr} L_{9}+R_{m}\left[-a L_{41}-b L_{40}-L_{53}-m_{1} L_{50}+\right. \\
&\left.L_{17}+\operatorname{Pr} L_{52}\right] \\
& Z= L_{0}\left(\operatorname{Pr}-m_{1}\right)+R_{m}\left[G_{1}\left(m_{1}-\operatorname{Pr}\right)-G_{2}\right]+\varepsilon I N I \cos (\omega t+\alpha) \\
& \quad I N I=\sqrt{ }\left(N_{r}^{2}+N_{i}^{2}\right) \quad \tan \alpha=N_{i} / N_{r}
\end{aligned}
$$

where $G_{1}, G_{2}$, a ,b, $L_{1}$ to $L_{52}$ are constants, their expressions are not presented here for sake of brevity. $\mathrm{R}_{\mathrm{m}}=0.05$ has been taken throughout the computations.

\section{Results and Discussions}

Table 1 , depicts that the skin friction coefficient at the plate increase with the increase in $\mathrm{K}_{0}, \mathrm{Gr}, \omega$, but decrease with increase in $\mathrm{M} \& \mathrm{Pr}$.

Fig 1 , It is seen that velocity profile $\mathrm{u}$ increases with increase in y for different values of permeability parameter $\mathrm{K}_{0}$, Grashoff number $\mathrm{Gr} \&$ frequency parameter $\omega$, but decrease with increase in Magnetic parameter M \& Prandtl number Pr.

Fig 2, It is seen that fluctuating parts of velocity profile $M_{r}$ decreases with increase in $\mathrm{K}_{0}, \mathrm{Gr}, \omega, \mathrm{M} \& \mathrm{Pr}$.

Fig 3, It is seen that fluctuating parts of velocity profile $\mathrm{M}_{\mathrm{i}}$ increases with increase in $\mathrm{K}_{0}, \operatorname{Pr} \& \mathrm{M}$ and decreases with increase in $\mathrm{Gr} \& \omega$. 
Fig 4 , It is seen that amplitude INI of the skin friction at the plate decreases with increases in $\mathrm{K}_{0}, \mathrm{Gr}, \omega, \mathrm{M}$ \& $\mathrm{Pr}$.

Fig 5 , It is seen that Phase lead tan $\alpha$ of the skin friction at the plate increases with the increase in $\mathrm{M}, \omega$ while tan $\alpha$ decreases with the increase in $\mathrm{K}_{0}, \mathrm{Gr} \& \operatorname{Pr}$.

Table 1: Values of skin- friction coefficient at the plate when $\varepsilon=0.2$

\begin{tabular}{|c|c|c|c|c|c|}
\hline $\mathrm{K}_{0}$ & $\mathrm{Gr}$ & $\mathrm{M}$ & $\mathrm{Pr}$ & $\omega$ & $\mathrm{C}_{\mathrm{f}}$ \\
\hline 0.3 & 4 & 5 & 0.71 & 4 & 1.12134 \\
\hline 0.4 & 4 & 5 & 0.71 & 4 & 1.17966 \\
\hline 0.3 & 8 & 5 & 0.71 & 4 & 2.24267 \\
\hline 0.3 & 4 & 7 & 0.71 & 4 & 1.00651 \\
\hline 0.3 & 4 & 5 & 1.0 & 4 & 1.01282 \\
\hline 0.3 & 4 & 5 & 0.71 & 8 & 1.2693 \\
\hline
\end{tabular}

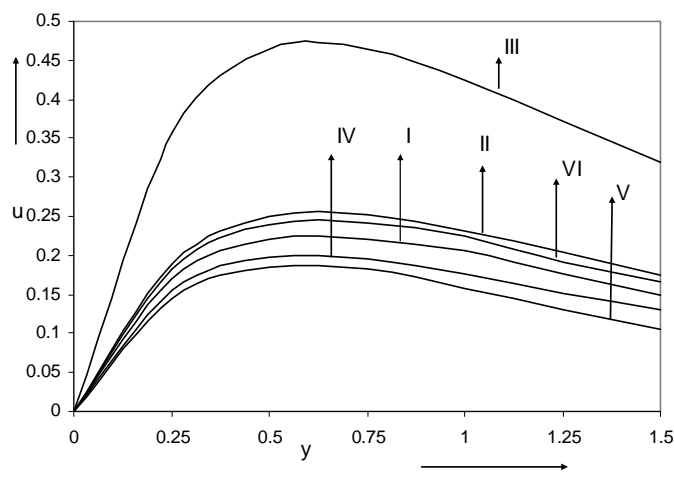

I $\mathrm{K}_{0}=0.3 \mathrm{Gr}=4 \mathrm{M}=5 \mathrm{Pr}=0.71 \omega=4$

II $\mathrm{K}_{0}=0.4 \mathrm{Gr}=4 \mathrm{M}=5 \mathrm{Pr}=0.71 \omega=4$

III $\mathrm{K}_{0}=0.3 \mathrm{Gr}=8 \mathrm{M}=5 \mathrm{Pr}=0.71 \omega=4$

IV $\mathrm{K}_{0}=0.3 \mathrm{Gr}=4 \mathrm{M}=7 \mathrm{Pr}=0.71 \omega=4$

$\mathrm{V} \quad \mathrm{K}_{0}=0.3 \mathrm{Gr}=4 \mathrm{M}=5 \mathrm{Pr}=1.0 \quad \omega=4$

VI $\mathrm{K}_{0}=0.3 \mathrm{Gr}=4 \mathrm{M}=5 \mathrm{Pr}=0.71 \omega=8$

Figure 1: Velocity Profile u against y.

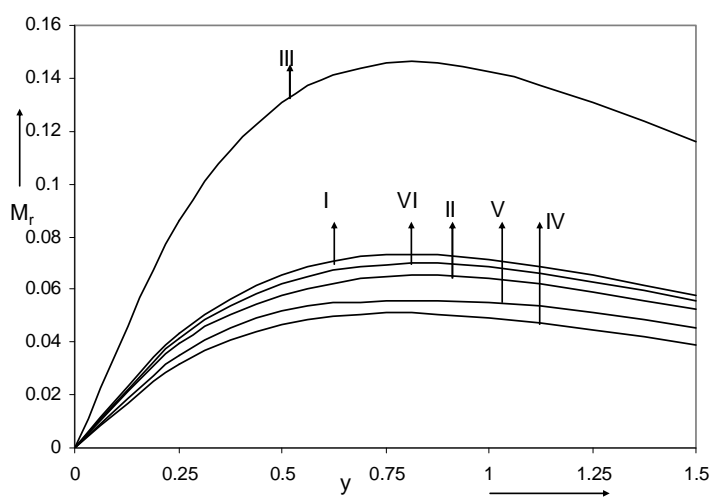

I $\mathrm{K}_{0}=0.3 \mathrm{Gr}=4 \mathrm{M}=5 \mathrm{Pr}=0.71 \omega=4$

II $\mathrm{K}_{0}=0.4 \mathrm{Gr}=4 \mathrm{M}=5 \mathrm{Pr}=0.71 \omega=4$

III $\mathrm{K}_{0}=0.3 \mathrm{Gr}=8 \mathrm{M}=5 \mathrm{Pr}=0.71 \omega=4$

IV $\mathrm{K}_{0}=0.3 \mathrm{Gr}=4 \mathrm{M}=7 \mathrm{Pr}=0.71 \omega=4$

$\mathrm{V} \mathrm{K}_{0}=0.3 \mathrm{Gr}=4 \mathrm{M}=5 \mathrm{Pr}=1.0 \omega=4$

VI $\mathrm{K}_{0}=0.3 \mathrm{Gr}=4 \mathrm{M}=5 \mathrm{Pr}=0.71 \omega=8$

Figure 2: Fluctuating parts of the velocity profile $\mathrm{M}_{\mathrm{r}}$ against $\mathrm{y}$. 


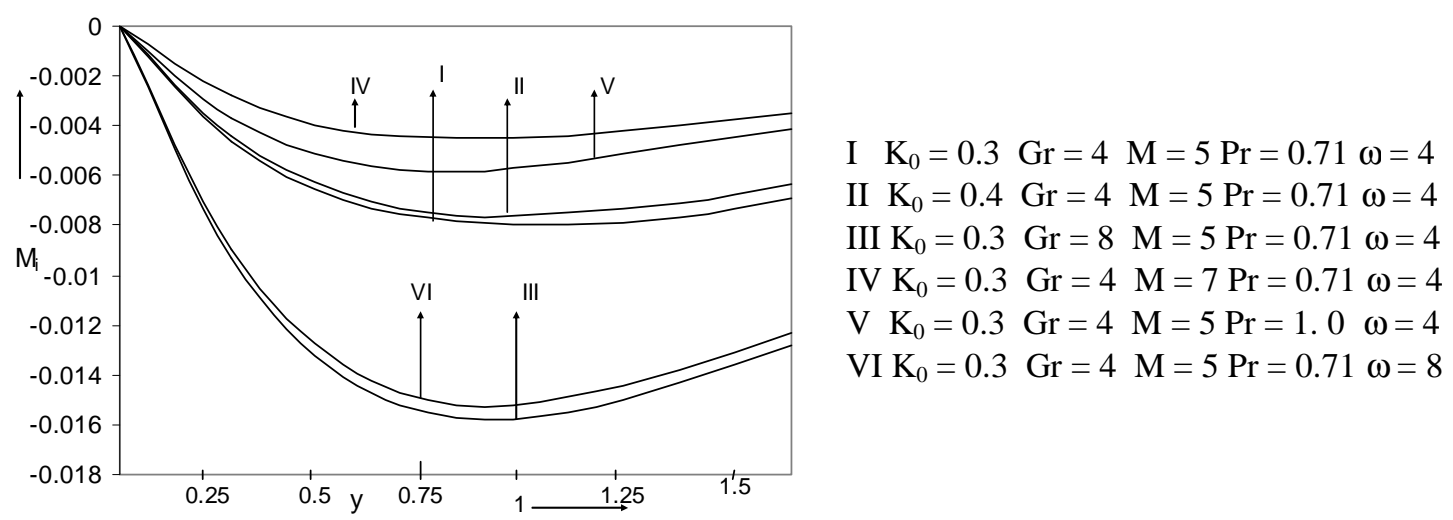

Figure 3: Fluctuating parts of the velocity profile $\mathrm{M}_{\mathrm{i}}$ against $\mathrm{y}$.

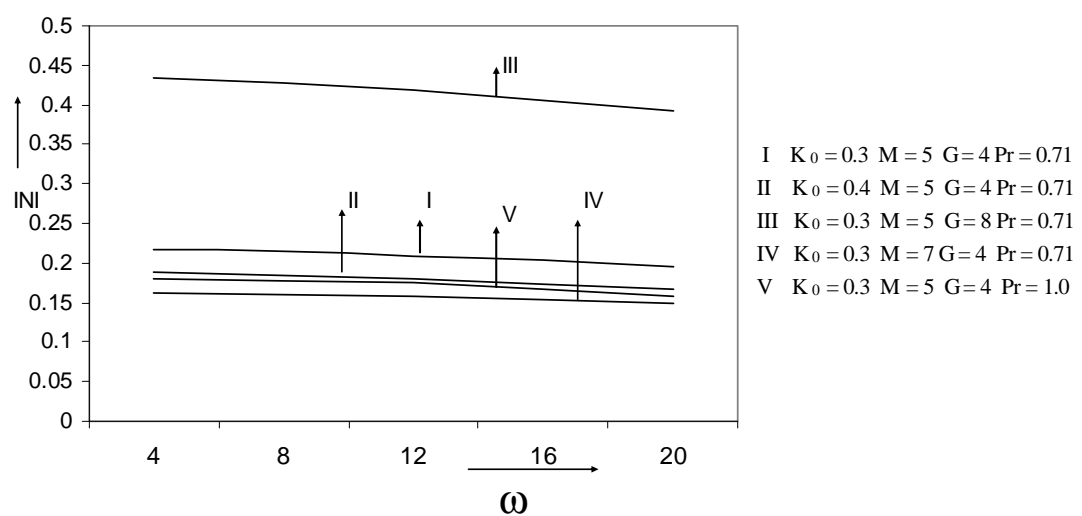

Figure 4: Amplitude of the skin friction against frequency parameter $\omega$.

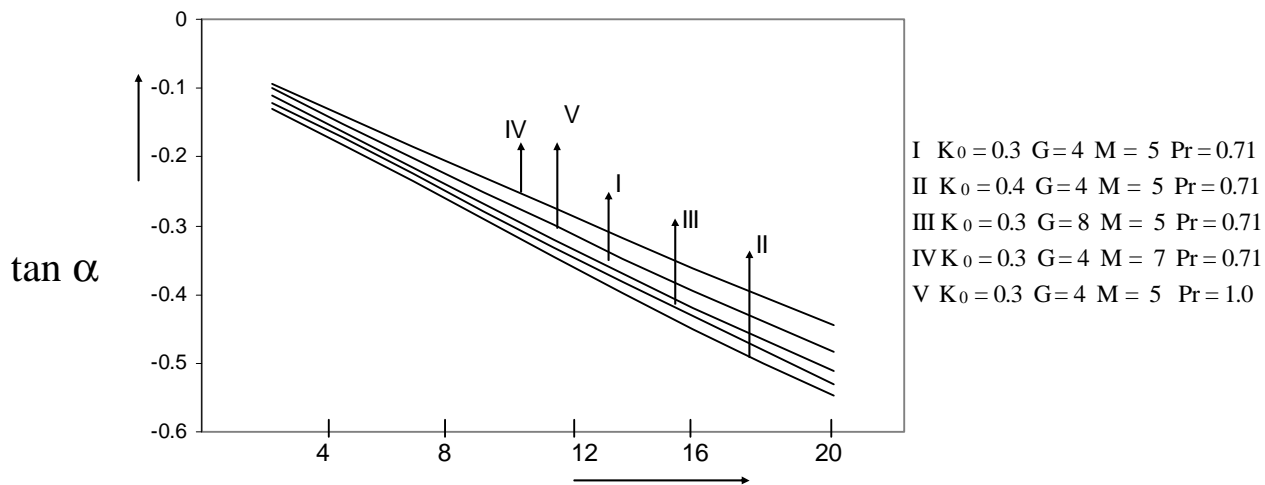

$\omega$

Figure 5: Phase lead of the skin friction $\tan \alpha$ against frequency parameter $\omega$. 


\section{References}

[1] Raptis,A., Perdikis,G., and Tzivandis G., 1981: .Phys. D. Appl.Phys,4 pp.99

[2] Raptis. A., 1983 : Unsteady free convection through a porous medium . Int. J. Engg. Sci ., 21,pp. 345.

[3] Raptis, A, Perdikis, G ,1985 : Int. J. Engg. Sci,23,pp.99.

[4] Chandrasekhara ,B.C, Namboodri, P.M.S and Hanumanthappa, A.S., 1984 : Similarity solutions or buoyancy induced flows in a saturated porous medium adjacent to impermeable surface, Warme - and - Stoffubertragung, vol (18 ), pp.17.

[5] Vedhanayagam M, Jain .P and Fairweather,G.,1987 : Int. comm. Heat mass Transfer 14,pp.495.

[6] Singh,P,Mishra, J.K and Narayana, K.A : Int. J. Numerical and Analytical Methods geomechanics ,13, (1989), p.443.

[7] Maharshi \& Tak,2000 : J. Indian.Acad.Math.vol 22,pp.293.

[8] Ahmed .S., and Ahmed .N.,2004 : Ind. Journal of Pure and Appl. Math.

[9] Sharma ,P.R., and Sharma.S.,2005 : Bull.Cal.Math.Soc,97(6), pp.477- 488.

[10] Sharma,P.R., and Yadav,G.R., 2006: Bull.Cal.Math.Soc,98(3), pp.237- 254.

[11] Sreekanth. S, Venkataramana. S and Ramakrishna. S.,1996 : Acta Ciencia Indica, Vol XXII M , N0.3, p.267.

[12] Noushima Humera,G., Ramana Murthy,M.V., Rafiuddin and ChennaKrishna Reddy,M., 2009 :Bull.Cal.Math.Soc,vol 101(3) , pp.281-290.

[13] Rivlin,R.S and Ericksen , J.L.,1955 : stress deformation relation for Isotropic Materials . Jour. Rat. Mech, vol 4, pp.323.

[14] Sparrow and Cess, 1962: Trans, ASME, J. Appl. Mech, vol 29,1, pp.181.

[15] Beard ,D. W and Walters,K.,1964 : camb. Phil. Soc.60, pp. 667. 
